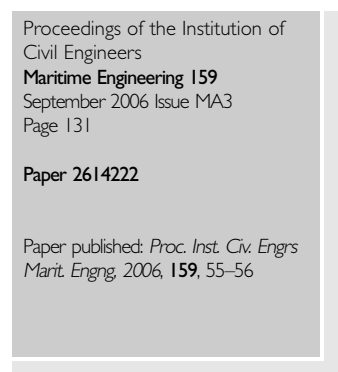

\title{
Discussion: The marine energy resource, constraints and opportunities
}

\section{G. Bryden}

\section{S. Maclntyre, Boreas Consultants, UK}

In my view there is a telling observation within the lifespan of this paper-and it is rather depressing-but since the paper was first filed over a year ago, very little has changed (with the important and notable exception that Pelamis is now being 'commercially' deployed in Portugal). It would be interesting to know how many conventional power plants have been brought on-line over the same time interval. In this light, I see little scope for optimism. The brutal facts are that the realisation of the tremendous potential of marine renewables remains as elusive as ever. I believe that it will remain so until we recognise (as a society) that the 'true' cost of energy is much higher than the cash price we currently enjoy. As Professor Bryden points out, the hidden subsidy for climate change and other ill effects of the fossil economy needs to be accounted for in some way and we need to face what might be an unpalatable truth, not bury our heads in the sand.

This 'truer cost' approach appears to be politically insupportable, so the debate should end there, yet successive generations of entrepreneurial spirited engineers continue to apply themselves to the thankless task of abstracting energy from the sea.

The final twist is that whilst for many the cost of energy is so low that it is not worth even conserving (witness countless examples of profligacy), for many others there is fuel poverty. In this context, what chance do marine renewables have?

There has to be a political will to find a more sustainable future that somehow also addresses the shame of fuel poverty, and for that to happen there needs to be a societal recognition that the way we account for our use of energy has to change. I think that finding a way through this challenge will require inspirational leadership, big thinking and even bigger actions, and I am sorry to say that I am sceptical on all three counts.

\section{Author's reply}

I agree that progress in marine renewable development can appear to be frustratingly slow. I do believe, however, that there are causes for qualified optimism.

Like Mr MacIntyre, I think that there are still many difficult barriers to be overcome before marine renewable energy can become a commercial reality. One of these is that there have been frequent over-optimistic assessments of the timescales associated with the development of a new industry and that, in many minds, failure to meet unrealistic predictions might be seen as overall failure. This would be a disaster for the industry and, I believe, the nation as it could allow a potentially world-leading industry to be lost to the UK. Politicians and decision makers must be guided by realism as well as enthusiasm. This country has lost other opportunities to develop new industries and I hope that it will not lose this one, especially if over-enthusiasm formed part of the mechanism of loss!

One very important major step forward since the paper was written is the construction of five full-scale test sites for tidal current devices in Orkney, as part of the European Marine Energy Centre. The first devices should be attached to the grid in the late summer of 2006. Similarly, the new Marine Current Technologies Ltd SeaGen tidal current device should be installed in Northern Ireland on a similar timescale.

In many ways we should consider ourselves to be at the marine renewable equivalent of the Wright brothers' stage of development of the aviation industry. We have made the first steps but it is going to take skill in the fields of fundamental research, system development, entrepreneurship and political vision to ensure that we move from the 'Flyer' to the 'Airbus' stage of development. Hopefully we have learned the lessons of other industries we pioneered in this country only to lose them through loss of vision. 